\title{
VR 3D Education for Vocational Training
}

\author{
Sven Maricic ${ }^{1 *}$, Donald Radolovic ${ }^{1}$, Ivan Veljovic ${ }^{1}$ and Roberta Raguz ${ }^{1}$ \\ ${ }^{1}$ Institute for Science and Technology Visio, University of Juraj Dobrila, Zagrebačka 30, \\ 52100 Pula, Croatia
}

\begin{abstract}
The progress and development in the fields of technologies in the past few decades are impressive. With so many innovations that have had an impact on human lives and have changed them so drastically, living in a time where new technologies are still making massive changes, and, unquestionably, it will continue with that trend. As the techniques are continuously evolving, people are forced to prepare ourselves and our descendants to the new and upcoming technologies so that they would be able to understand them, use them, teach others about them and also make some improvements in the specific fields of applications. This article presents an overview of the principal results of research on the impact of Virtual Reality (VR) 3D education for students in industrial vocational training. They were introduced to the generated model and had to explore all elements to have personal experience in the virtual environment. After the training, a user experience survey has been conducted, and the results obtained after the use of the system were presented.
\end{abstract}

\section{Introduction}

Virtual Reality (VR) is the way of using computer technology to create a simulated environment under controlled conditions. Unlike traditional user interfaces, the VR user interface sets users within the experience. Thus, it enables them to have hands-on experience regardless of his location. Instead of looking at the screen in front of them, users realise direct interaction and actively participate in content analysis. By simulating as many senses as possible such as vision, hearing, touch and smell, the computer becomes an essential tool. Virtual reality is an advanced technology that enables user experience of visiting a given space or can be used to educate new models as well as their analysis [1 -5]. VR creates a 3D image representation on special glasses that surrounds the user which gives him the feeling of being in a specific place without physical departure to that place or giving him the feeling of being in a particular situation. In this context, the $3 \mathrm{D}$ modelling process in which a mathematical representation of a three-dimensional object is projected is of crucial importance. The result is a $3 \mathrm{D}$ model that can be rendered as a $2 \mathrm{D}$ image or can be used as a resource in a real-time graphics simulation. It contains data about the 3D space points and other information that the computer interprets into a virtual object that is plotted on the screen. This paper shows that through the use of new technologies such as VR and $3 \mathrm{D}$ modelling learning and teaching process in vocational studies can be improved. The paper presents a 3D virtual product model. Based on the shown 3D virtual model, a user survey was conducted.

\footnotetext{
*Corresponding author: smaricic@unipu.hr
} 


\section{Usage of virtual reality and $3 d$ modelling in the learning process at vocational studies}

Virtual reality offers a wide range of benefits to the learning process. By using VR and 3D modelling in the process of learning at vocational studies, students are provided numerous opportunities that cannot provide them with a classical form of a lecture. By researching these areas and technologies, it can be concluded that VR and 3D modelling trends are rapidly expanding and affecting all spheres of life $[3,4,6]$. Virtual reality was primarily used as a technology to improve computer gaming experience, but today it is developing intensively in other directions too. The application can also be found in the field of education. The link between VR, 3D modelling and learning or training is that this process should be an easy, exciting and challenging experience, same as VR and 3D modelling. The traditional form of learning and teaching cannot provide that experience, but with the application of these relatively new technologies, it becomes possible. VR is the perfect way to transfer information to groups where students have different abilities and groups where students learn in different ways and differently perceive teaching contents. Using VR, through a three-dimensional audiovisual presentation of content, learning is made more effective and new information that students are quoting are more persistent. By using VR and 3D modelling in the learning process, student's motivation is also growing, which is one of the crucial factors for successfully mastering new information [6-9]. Teaching methods become more diverse and do not prevail, only verbally. Visual and practical methods become equally important and used in present vocational studies.

Some of the main reasons [5-7] to apply VR and 3D technologies in the learning process at vocational studies are:

- Developing and encouraging creativity

- Improving knowledge

- Development of digital competence

- Development of technical capabilities

- Competence development "learn how to learn"

- Development of cognitive (metacognitive) skills

- Developing a constructivist learning environment

- Development of critical thinking, communication and collaboration among students - development of social skills

- The ability to find better jobs, or those that are growing demand

\section{Research methodology and results}

At a methodology level, the paper assumes a VR model overview to test a conceptual framework of possible alternative education phase for vocational studies. A learning model has been created to check on students' acceptance and use of realistic simulation technologies for education. The main aim of the research is through a three-dimensional audio-visual presentation of content to create a hands-on experience for students. The answers offered according to a five-degree Likert-type scale (gradually from 1- I am not at all, 5- I am extremely/fully). The study attempts to identify an answer for two main topics and their subsequent questions, as follows:

1. Determine "if and how initial education influences the adoption of VR technologies for vocational education students" - having as following questions: "How satisfied are you with the quality of the virtual model?", "How informed are you about the application of new technologies in educational activities in the process industry?";

2. Identify "satisfaction of users and in which way this type of education is connected to the Unified Theory of Acceptance and Use of Technology (UTAUT/UTAUT2) model" supposing as questions: "Do you think that the implementation of 3D models would 
contribute to a significant improvement of the quality of teaching?", "Do you think that the design and implementation of 3D models should be introduced into regular teaching at the vocational study?", "Do you think that the implementation of VR 3D models would contribute to a significant improvement of vocational training?".

\section{CAD model generation}

CAD stands for Computer-Aided Design, and this type of programs are being used to create virtual 3D models on the computer. These models can help make improvements in different aspects such as functionality, design or ergonomic properties. Using the CAD models, users can create specific work drawings, and assembly drawings for production render of the model and even VR (virtual reality) models. Also, one of the essential things about the usage of the presented 3D model is its universal format compatible on a large scale of modern devices. To create the VR industrial environment equipped with robotic arms and conveyor lines, Autodesk Fusion 360 has been used. Other than just being a CAD software, Fusion 360 is a multi-solution cloud-based software that includes some of CAE tools - CAM, FEM. Being cloud-based it allows the participation of an entire team working on a single project. The program has a clear simple and user-friendly interface shown in figure 1.

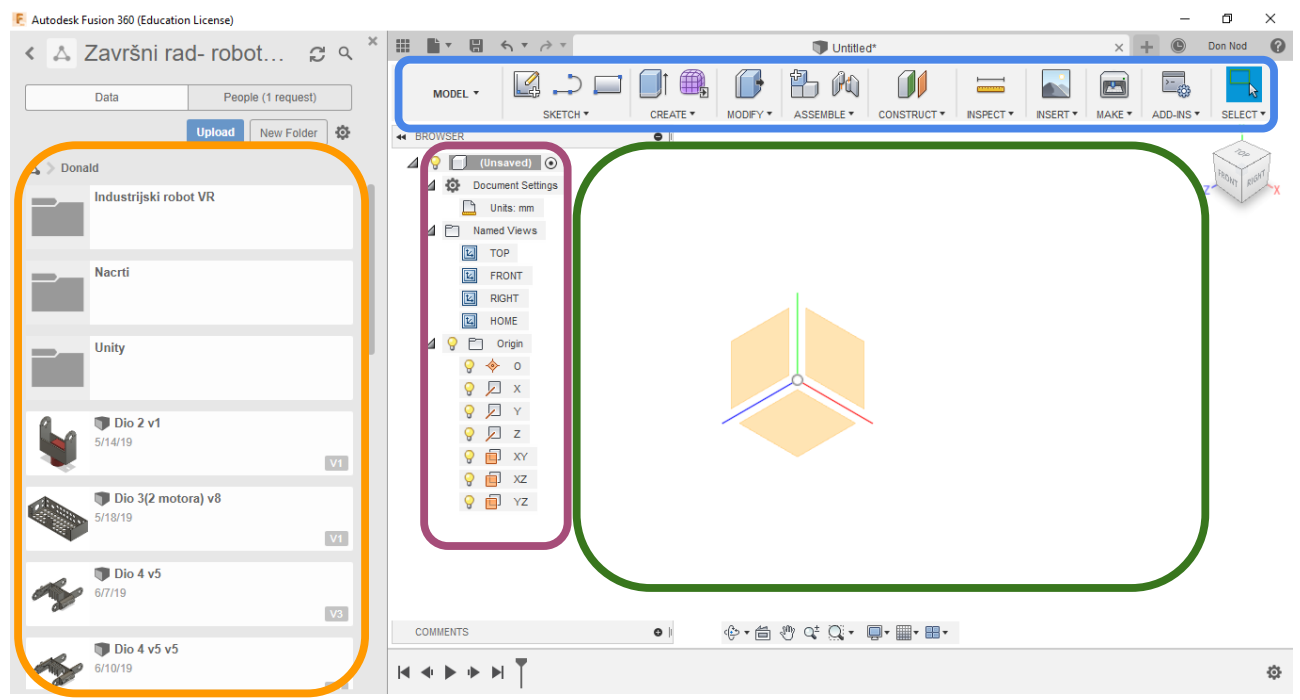

Fig. 1. Autodesk Fusion 360 user interface (UI), [10].

The user interface is divided into four major parts: Toolbar, Browser, Workspace and the Cloud area. This paper presents a short overview of step by step process. All the components for the robotic arm are modelled, but instead, this paper will show just the final product and its components (Fig. 2).
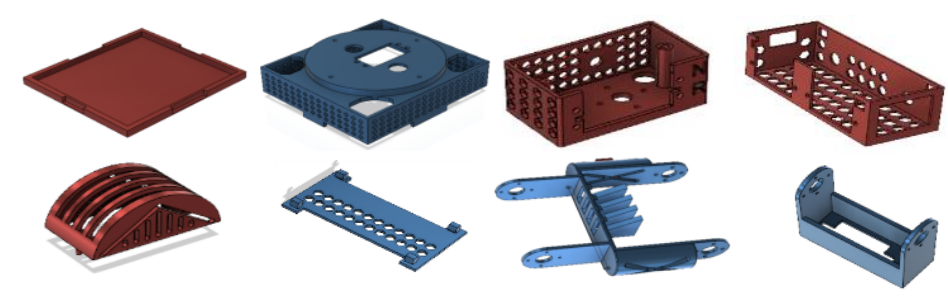

Fig. 2. CAD - generated robotic arm components, [10]. 


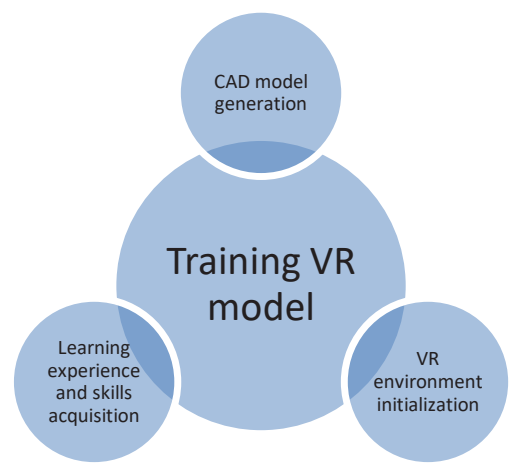

Fig. 3. Phases of training model generation.

Figure 3 presents several steps in planning, initialisation of the VR environment with physical and virtual model pairing - learning experience and skills acquisition. For research purposes, for a better comparison of the physical and virtual models, a 3D model was also built. It consists of nine parts, which were the first 3D modelled, and then 3D printed. The motion of the robotic arm driven by five servo drivers, controlled using a motherboard, giving the arm five degrees of freedom (DOF), presented in figure 4. After generating the virtual model, it is easy to produce a physical model with 3D print which is in figure 5 .

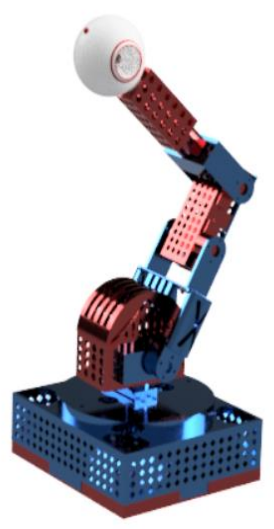

Fig. 4. A rendered CAD model of the robotic arm.

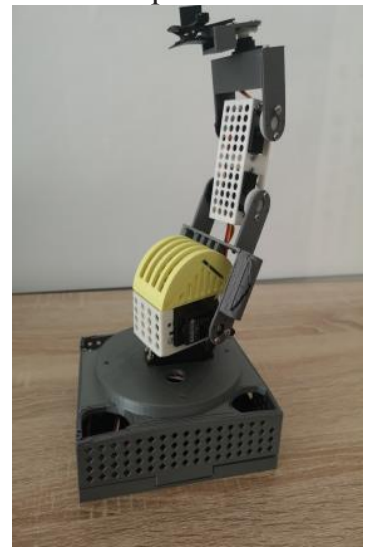

Fig. 5. 3D printed prototype of the robotic arm.

The robotic arm is used for creating the industrial environment with production lines (Fig. 6). The model presented in figure 6 is an educational model that is built for educational purposes.

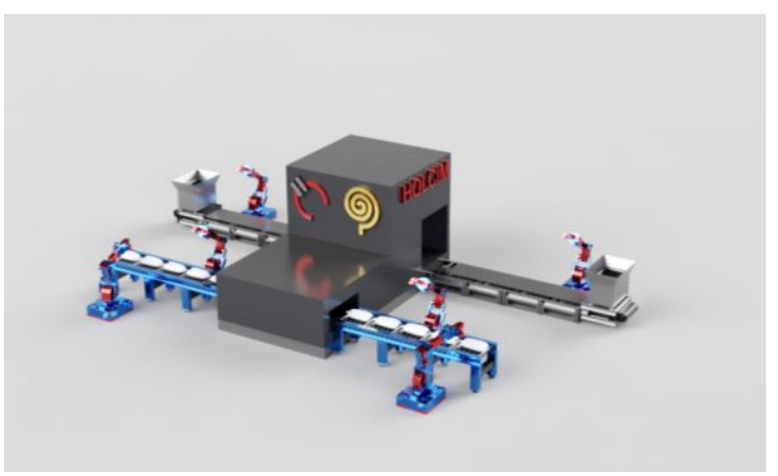

Fig. 6. Generated virtual industrial environment for vocational education training [10]. 


\section{Survey}

In total, 58 students were included with different previous educational background. Presented survey consists of the following questions:

1. Do you think that the design and implementation of $3 \mathrm{D}$ print models should be introduced into regular teaching at a vocational training?

2. How satisfied are you with the quality of the virtual model?

3. Do you think that the implementation of $3 \mathrm{D}$ models would contribute to a significant improvement of vocational training?

4. How informed are you about the application of new technologies in educational activities in the process industry?

5. Do you think that the implementation of $3 \mathrm{D}$ models would contribute to a significant improvement in the quality of teaching?

At the beginning of the survey, students were given access to the virtual model and provided them with a guide for use. A link to the virtual model on which education was provided was also attached. After that, they followed brief instructions for users to get hands-on through the 3D model preview software. The survey was set up bilingual in Croatian and English to cover as many different students as possible. Poll questions were closed type. The answers offered were the option of choosing between answers yes/no or they were given on a five-degree Likert-type scale (gradually from 1- I am not at all, 5- I am extremely/fully). According to $[11,12]$, one of the recommendations for measuring of UTAUT/UTAUT2 is to conceptualise individual technology, use at the feature level and use it as the baseline model to refine the conceptualisation and measurement of the current context factors that have impacts on feature-level use.

\subsection{Student survey analysis}

The results show students opinion on how the use of 3D models in VR influences teaching at vocational studies. It is also shown how well students are satisfied with the quality of a virtual model and their commitment to the application of new technologies in educational activities in the process industry. Out of a total of 58 respondents, 22 were male gender $(37.5 \%)$ and 35 females gender $(60.8 \%)$ and 1 who did not want to declare gender $(1.7 \%)$. The age of respondents was different. Most of the respondents were of the age 21-23 $(61.5 \%)$, then respondents aged 24-27 (17.5\%), and respondents aged 18-20 and 28+ were equal $(10.5 \%+10.5 \%)$ as can be seen in table 1 .

Table 1. Table of the respondents by age and gender.

\begin{tabular}{|c|c|c|c|c|}
\hline Age & M & F & No answer & Total \\
\hline $18-20$ & 3 & 3 & 0 & 6 \\
\hline $21-23$ & 9 & 26 & 0 & 35 \\
\hline $24-27$ & 5 & 5 & 1 & 11 \\
\hline $28+$ & 5 & 1 & 0 & 6 \\
\hline Total & 22 & 35 & 1 & 58 \\
\hline
\end{tabular}

Most of the respondents were from the 3rd year of the faculty, with a total of 31 students. From the other years, they were equally alike. 6 in the first year, 8 in the second year, 6 in the fourth year, 4 in the fifth year, and 3 in postgraduate studies. Since their answers were very similar, the splitting of the results by gender is presented as overall percentages. 
In question 1: Do you think that the design and implementation of 3D models should be introduced into regular teaching at a vocational training? $96.4 \%$ of respondents believe that the design and implementation of 3D models should be introduced into regular teaching at the vocational training. $3.6 \%$ of respondents believe they should not be introduced (Table 2).

Table 2. Table of the respondents.

\begin{tabular}{|c|c|c|c|c|}
\hline & Yes & $\%$ & No & $\%$ \\
\hline Total & 56 & 96.4 & 2 & 3.6 \\
\hline
\end{tabular}

In question 2: How satisfied are you with the quality of the virtual model? Overall, $59.6 \%$ of respondents are very or very satisfied with the quality of the virtual model. $29.8 \%$ are not sure, neither satisfied nor dissatisfied, while $3.5 \%$ of respondents stated that they are not satisfied. By gender distribution, more male respondents are satisfied with the model (72.7\%) (Fig. 7).

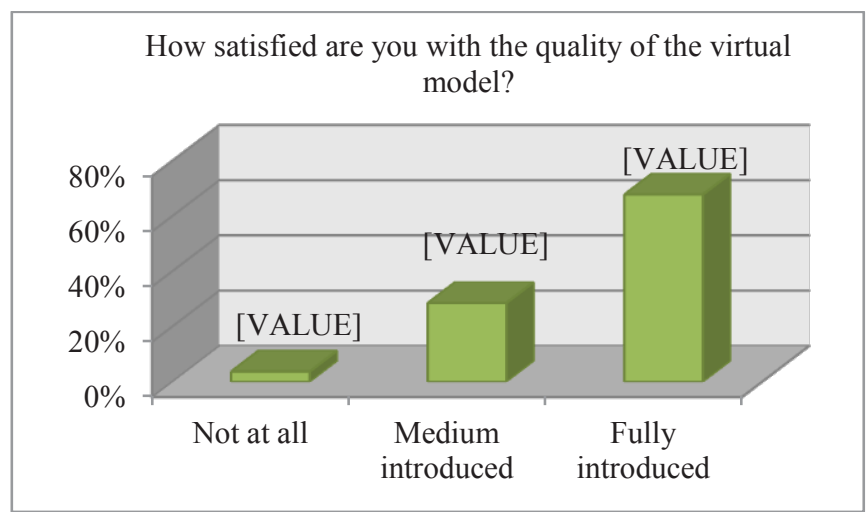

Fig. 7. Graphical representation of responses on a second question.

In question 3: Do you think that the implementation of 3D models would contribute to a significant improvement of vocational training? Overall, $94.7 \%$ of respondents responded positively to this question and considered that the $3 \mathrm{D}$ model application would contribute to a significant improvement in vocational training, while $5.3 \%$ of the respondents believe that the application of the $3 \mathrm{D}$ model would not contribute to a significant improvement in vocational training (Fig. 8).

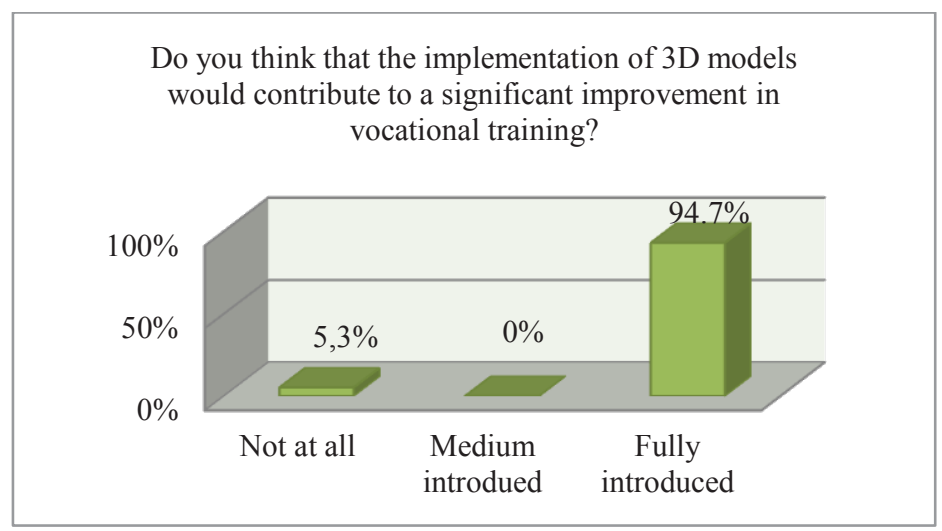

Fig. 8. Graphical representation of responses on a third question. 
In question 4: How informed are you about the application of new technologies in educational activities in the process industry? Obtained results show that introduction in the application of new technologies in educational activities in the process industry of the respondents is average. Most respondents (43.9\%) replied that they are medium introduced, $24.6 \%$ are fully introduced while $29.8 \%$ of respondents are not introduced at all (Fig. 9).

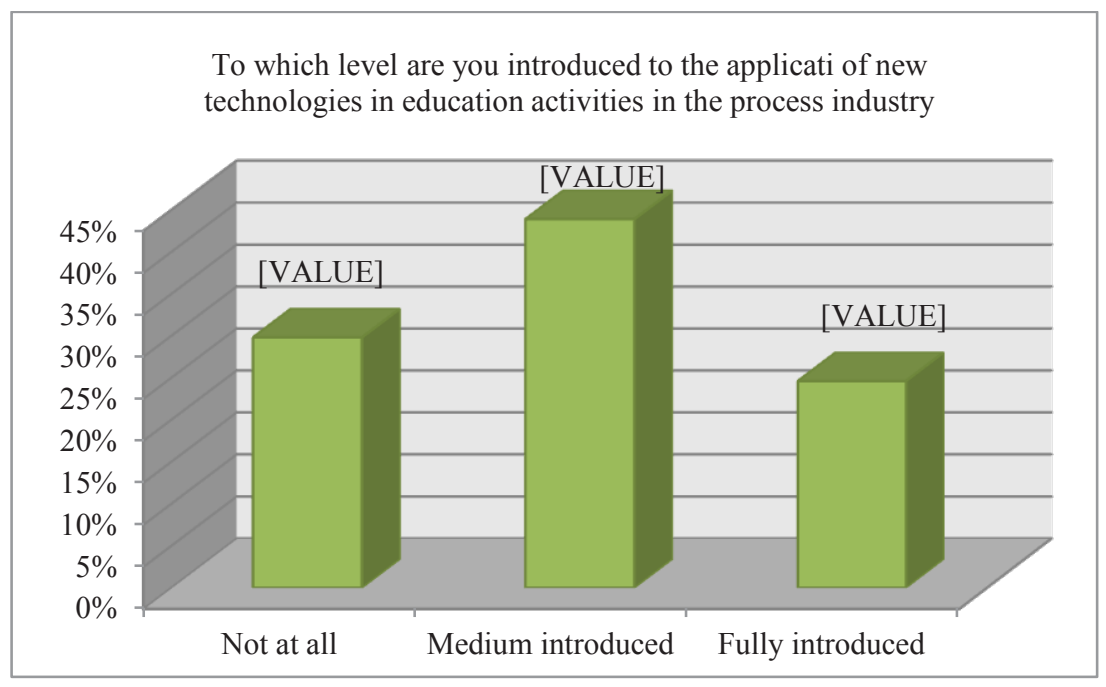

Fig. 9. Graphical representation of responses on a fourth question.

On the last question regarding the implementation of 3D models and its possible contribution to a significant improvement of the quality of teaching, respondents answered $93.0 \%$ positive. Which would mean that $93 \%$ of them consider that the application of $3 \mathrm{D}$ models would contribute to a significant improvement in teaching. Only $7 \%$ of them think that applying 3D models would not bring significant improvement in teaching (Fig. 10).

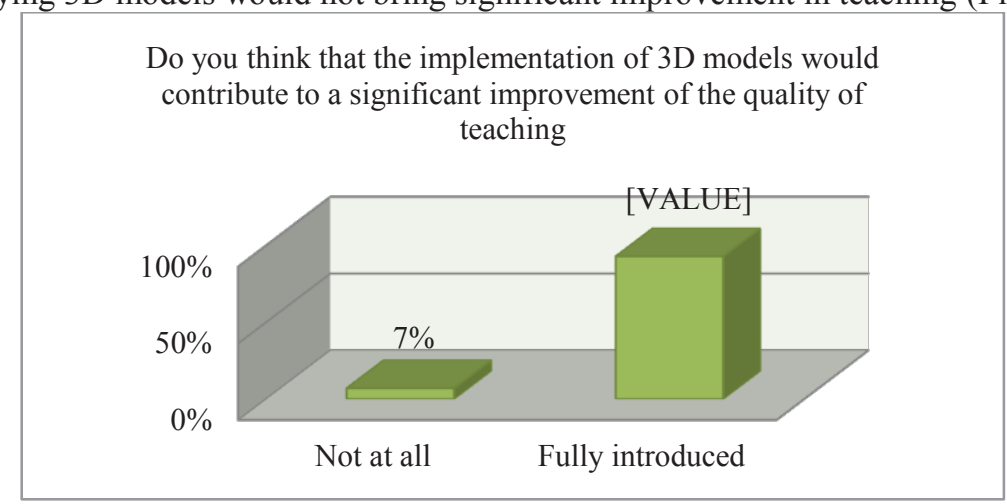

Fig. 10. Graphical representation of responses on a fifth question.

\section{Conclusions}

Throughout history, people have faced moments of great discoveries that have brought us many benefits. With technological development and advancement, new opportunities are rising fast. In this paper, we wanted to present a VR model as an alternative method of learning and teaching in fast-growing field of acceptance and use of technology (UTAUT/UTAUT2) in vocational studies. A learning model has been created to check on 
students' acceptance and use of realistic simulation technologies for education. After gained experience with the VR model, a user experience survey was conducted. In total, a group of 58 students filled the questionnaire. The answers were divided between the option of choosing answers yes/no, or they were given on a five-degree Likert-type scale. Most of the respondents were of the age 21-23 (61.5\%), 24-27 (17.5\%), and respondents aged 18-20 and $28+$ were equal $(10.5 \%)$. In the presented case, vast majority of students $(94.7 \%)$ think that the use of 3D VR model as a learning model would significantly improve their learning experience. Also, just $5.3 \%$ of the respondents believe that the application of the $3 \mathrm{D}$ model would not contribute to a significant improvement in vocational training. Based on the presented results, VR technology could be a valuable tool in the new educational approach.

This article was made under the support of DYNAMIC project - 588378-EPP-1-2017-1-DEEPPKA2-KA, Towards responsive engineering curricula through europeanisation of dual higher education.

\section{References}

1. C. Uloyol, S. Sahin, Augmented Reality: A New Direction in Education: Emerging Tools and Applications of Virtual Reality in Education (2016)

2. X. D. Luan et al., IJCSNS International Journal of Computer Science and Network Security, 8, 1 (2008)

3. C. Christou, Virtual Reality in Education. https://www.researchgate. net/publication/272677840_Virtual_Reality_in_Education (2010)

4. A. Bernik, Tehnički glasnik. 4, (2010)

5. D. Ilić, M. Jurešić, K. Vulinović, Virtualna stvarnost u obrazovanju. https://radovi2016.cuc.carnet.hr/modules/request.php?module $=$ oc_program\&action $=$ vi ew.php\&id=92\&type $=2 \& \mathrm{a}=(2016)$

6. J. Gaudiosi, These Two School Districts Are Teaching Through Virtual Reality. Available on: http://fortune.com/2016/02/25/school-districts-teaching-through-virtualreality/ (2016)

7. S. Choi, K. Jung, S. Do Noh, SAGE Journals; 23, 1, (2015)

8. Y. N.Zheng, J.Y.S. Luh, P. F. Jia, Computers in Industry, 12, 4, (1989)

9. B. Berman, Business Horizons, 55, 2, (2012)

10. D. Radolović, 3D Modelling and Robotic Arm Control; University of Juraj Dobrila, Bachelor Thesis, Pula, Croatia (2019)

11. V. Venkatesh et al.; JAIS, 17, 5, (2016)

12. Y.K. Dwivedi et al.; Inf Syst Front 21, (2017) 